\title{
About idiopathic chylopericardium: a case report
}

\author{
Mirko Barone $^{1 *}$, Marco Prioletta ${ }^{1}$, Giuseppe Cipollone ${ }^{1}$, Decio Di Nuzzo ${ }^{1}$, Pierpaolo Camplese ${ }^{1}$ and Felice Mucilli $^{1}$ \\ ${ }^{1}$ Department of General and Thoracic Surgery, University Hospital “SS Annunziata”. University “G. d'Annunzio”, Italy
}

\begin{abstract}
Idiopathic chylopericardium is a rare clinical entity, whose precise etiology is still unclear and few cases are reported till this date. This case report describes the history, physical examination, evaluation, diagnosis and treatment of a 45-years-old male patient with primary idiopathic chylopericardium. Radiological findings and biochemical analysis of the pericardial fluid following pericardiocentesis sustained this diagnosis.
\end{abstract}

\begin{abstract}
Abbreviations: CT (Computed tomography), TPN (total parenteral nutrition), VATS (video-assisted thoracic surgery).
\end{abstract}

\section{Introduction}

The accumulation of chylous fluid in the pericardial sac, chylopericardium, is a condition that usually occurs after trauma, surgery, tumors and infectious diseases [1]. Congenital lymphangioleiomyomatosis or lymphangiectasia may also cause chylopericardium [2]. However, idiopathic chylopericardium is a rare clinical entity, whose precise etiology is still unclear.

\section{Case report}

A 45-years-old male patient was referred to our Department for the management of a pericardial effusion. His chief complaints were moderate exertional dyspnoea, cough and previous fever spikes. He denied a history of trauma, neoplasms, radiation or infections and had a remote history of ischemic heart disease treated with angioplasty and of gastric ulcer. Past medical, surgical and remaining histories were not significant. Pericardial effusion was incidentally found at an echocardiogram. Despite medical treatment, pericardial effusion was still noted in follow-up echocardiography (Figure 1). Chest $\mathrm{x}$-ray showed an enlarged cardio-mediastinal shadow, while chest CT detected a $5 \mathrm{~mm}$-right upper lobe pulmonary nodule, diffuse mediastinal lymphadenopathy and the presence of a $20 \mathrm{~mm}$ circumferential pericardial effusion. Laboratory findings did not show any signs of inflammation (WBC $6.55^{*} 10^{3} / \mathrm{uL}, \mathrm{C}$-reactive protein concentration less than $0.5 \mathrm{mg} / \mathrm{dl})$. The patient underwent pleuropericardial window and thoracic duct ligation via right thoracotomy at the sixth intercostal space (Figure 2). Cytologic examination revealed a lymphocyte-dominant cell count with no malignant cells. Bacterial cultures were sterile and pathologic examination of the pericardium demonstrated no evidence of malignancy. The early postoperative course was regular and the patient was kept with nilper-mouth, antibiotic and somatostatin analogues $(0.2 \mathrm{mcg}$ once a day) administration. In sixth post-operative day, basal chest tube was removed. By the second postoperative week, ipolipidic diet was introduced but the fluid reaccumulated to about $400 \mathrm{ml}$ per day. Biochemical analysis fluid showed an elevated triglyceride level (397 $\mathrm{mg} / \mathrm{dL}$ ), a cholesterol-triglyceride ratio $<1$ and high amylase and lipase levels (126 U/l and $2490 \mathrm{U} / \mathrm{l})$. Moreover, laboratory parameters showed signs of hypoproteinemia $(5.0 \mathrm{~g} / \mathrm{dl})$, hypoalbuminemia $(2,610 \mathrm{mg} /$ dl) and chest CT demonstrated the presence of massive right pleural effusion with lung collapse and mediastinal shift (Figure 3). A right chest drainage was placed with a fluid accumulation of $2800 \mathrm{cc}$ in 24 hours. A conservative approach was adopted by keeping the patient with total parenteral nutrition (TPN) and by increasing somatostatin analogs administration $(0.2 \mathrm{mcg}$ three times a day). Despite supportive treatment, a moderate leukopenia (WBC $\left.4.2{ }^{*} 10^{3} / \mathrm{uL}\right)$ associated with weight loss was recorded.

During the fourth postoperative week, the patient complained of generalized itching with the appearance of diffuse papules. After consultation with dermatologists, a parasitosis was diagnosed and the patient was transferred to the Department of infectious diseases where he stayed for about a week.

On readmission, considering the defedate clinical conditions, a conservative strategy was continued and a chemical pleurodesis (povidone-iodine) was undertaken. The effusion gradually decreased to about $50 \mathrm{ml}$ per day and chest tube was removed. The patient was discharged on the eighty-fifth postoperative day.

\section{Discussion}

The accumulation of chylous fluid in the pericardial sac, chylopericardium, is a condition that usually occurs after trauma, surgery, tumors and infectious diseases [1]. Congenital lymphangioleiomyomatosis or lymphangiectasia may also cause chylopericardium [2].

Etiology remains unclear, although several theories have been proposed. To this date, structural and dynamic anomalies of lymph flow (lymph leakage, damage to thoracic duct valves, presence of abnormal communication between the thoracic duct and the pericardial sac) resulting in a retrograde reflux and in an increased capillary permeability are recognized. Clinical manifestations vary

Correspondence to: Mirko Barone, Department of General and Thoracic Surgery, University Hospital "SS Annunziata". University "G.d'Annunzio". Via dei Vestini n.1, 66100 Chieti , Italy, Tel: +39 0871/358289; Fax: +39 0871/358220; E-mail:mir87mb@libero.it

Key words: chylopericardium, pericardial window, thoracic duct

Received: May 04, 2017; Accepted: May 16, 2017; Published: May 19, 2017 


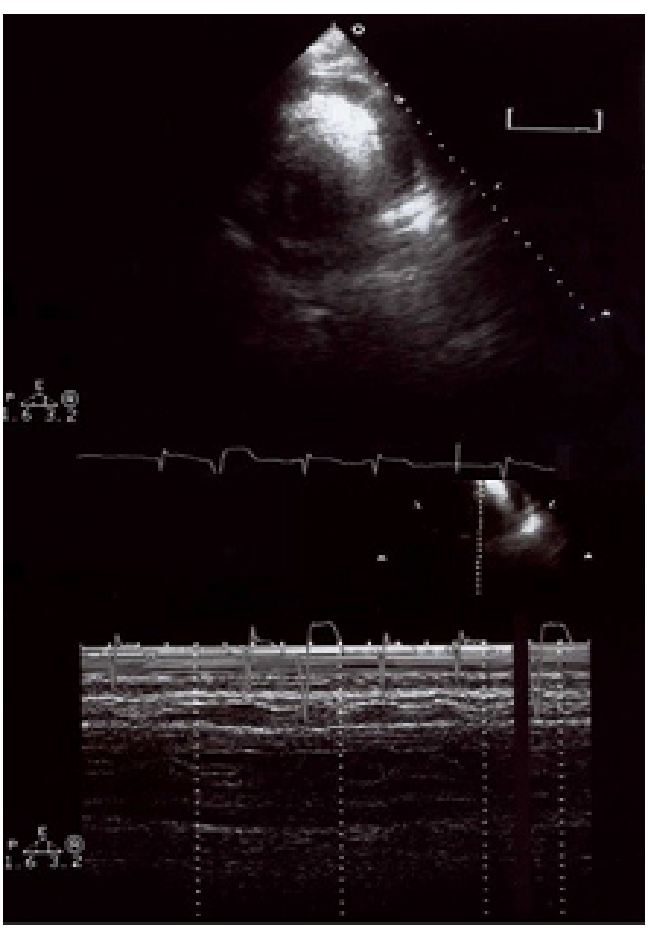

Figure 1. Preoperative echocardiogram: pericaldial fluid collection
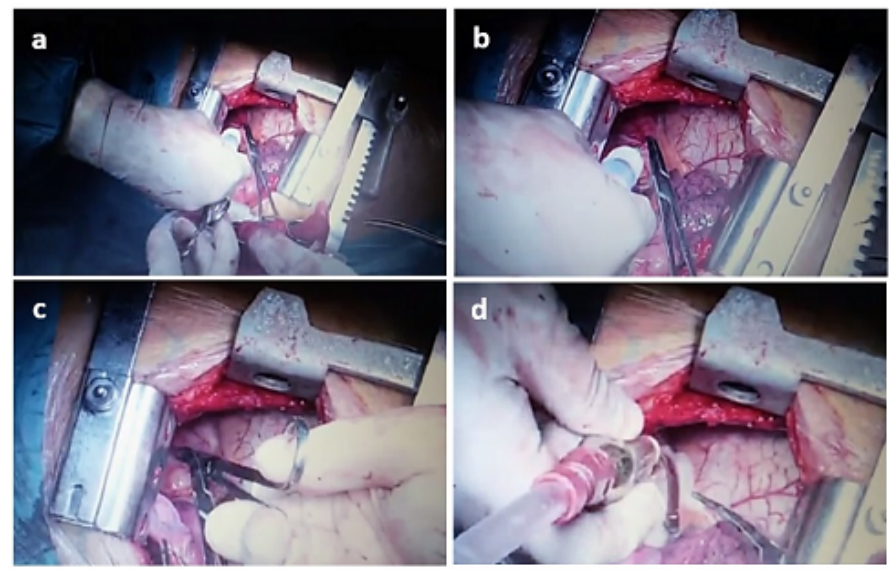

Figure 2. Pleuro-pericardial window via right thoracotomy at the sixth intercostal space (a.b. intraoperative pericardiocentesis; c.d. pleuro-pericardial window packing)

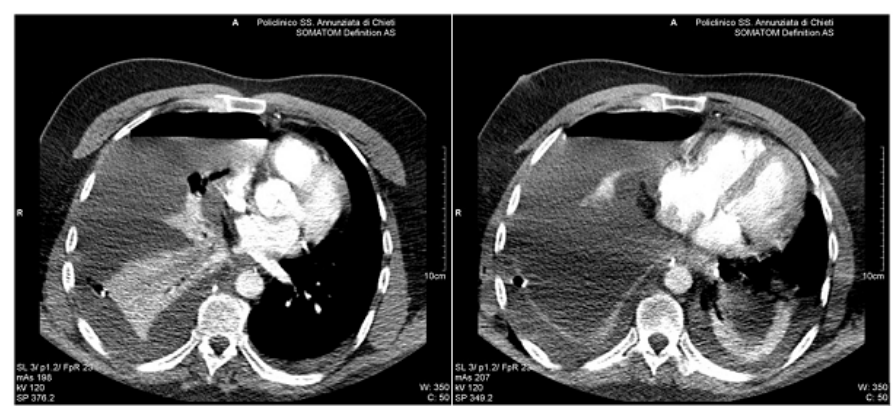

Figure 3. Postoperative chest CT: massive right pleural effusion with mediastinal shift.

from asymptomatic to life-threatening conditions such as the onset of cardiac tamponade. Diagnosis is usually accidental and wit patients complaining non-specific symptoms (i.e., cough, dyspnea, palpitations) [3].
Chest X-ray shows a cardiac shadow enlargement, while CT or MRI of the mediastinum are focused on the detection of infectious and neoplastic diseases. Lymphangiogram and lymphoscintigraphy can also demonstrate the presence of anomalous mediastinal ducts, the presence of fistulas or a thoracic duct's aplasia [4]. On electrocardiography, non-specific flattening $\mathrm{T}$-waves are present; while, echocardiography demonstrates the presence of pericardial effusion. Diagnosis requires a pericardial fluid collection, which is characterized by a milky appearance, triglycerides $>500 \mathrm{mg} / \mathrm{dl}$, a cholesterol/triglycerides ratio $<1$, by the presence of a relative lymphocytosis and by the absence of microrganisms [5].

Treatment is based on prevention of cardiac (pericarditis, electro-mechanical dissociation, cardiac tamponade), matabolic and immunological complications and it usually starts with a conservative and a dietary approach, associated with parenteral nutrition and octreotide administration (100 micrograms trice a day), thus reducing ileal absorption [6]. Ethylephrine increases lymphatic drainage by acting on the vessels'muscularis. However, this strategy presents high failure rates up to $60 \%$ and therefore, in the absence of an early improvement ( $<2$ weeks), it should be discontinued and surgery both in symptomatic patients and in asymptomatic ones should be considered [7].

Pericardiectomy is effective in preventing recurrences, but postoperative myocardial hernias are life-threating complications. On the other hand, open or VATS pleuro-pericardial window is a simple procedure but with a high risk of relapse. Therefore, the thoracic duct ligation has to be associated [1]. Although in the thorax, it is accessible both from a right and a left approach, the previous is preferred for anatomical reasons. In fact, on the right, it lies between the azygos vein and the descending aorta, while on the left, exposure is difficult due to the presence of the heart and the aorta itself. A transabdominal ligation, after a pericardium-peritoneal window packing, has been described and therapeutic alternatives are the Denver's pericardial-peritoneal shunt and percutaneous embolization procedures [8].

In conclusion, idiopathic chylopericardium is a rare condition with a fearsome systemic evolution. Our case demonstrated a synergetic cooperation is needed for the choice of the best available therapeutic strategy.

\section{References}

1. Akamatsu H, Amano J, Sakamoto T, Suzuki A (1994) Primary chylopericardium. Ann Thorac Surg 58: 262-266. [Crossref]

2. Ferrans VJ, Yu ZX, Nelson WK, Valencia JC, Tatsuguchi A, et al. (2000) Lymphangioleiomyomatosis (LAM): a review of clinical and morphological features. $J$ Nippon Med Sch 67: 311-329. [Crossref]

3. Raza M, Matar K (2009) Idiopathic chylothorax and chylopericardium resistant to conservative and surgical management. Heart Lung Circ 18: 229-232. [Crossref]

4. Nanjo S, Yamazaki J, Tsubuku M, Ohyama T, Ohtsuka T, et al. (2004) Primary idiopathic chylopericardium: report of two cases. Ann Nucl Med 18: 537-539. [Crossref]

5. Dib C, Tajik AJ, Park S, Kheir ME, Khandieria B, et al. (2008) Chylopericardium in adults: a literature review over the past decade (1996-2006). J Thorac Cardiovasc Surg 136: 650-656. [Crossref]

6. Szabados E, Toth K, Mezosi E (2011) Use of octreotide in the treatment of chylopericardium. Heart Lung 40: 574-575. [Crossref]

7. Bhat P, Ananthakrishna R, Panneerselvam A, Yalagudri SD, Rao PS, et al. (2011) Recurrent chylopericardium. BMJ Case Rep 2011. [Crossref]

8. Courtney M, Ayyagari RR (2015) Idiopathic chylopericardium treated by percutaneous thoracic duct embolization after failed surgical thoracic duct ligation. Pediatr Radiol 45: 927-930. [Crossref]

Copyright: C2017 Barone M. This is an open-access article distributed under the terms of the Creative Commons Attribution License, which permits unrestricted use, distribution, and reproduction in any medium, provided the original author and source are credited. 